\author{
Federal Reserve Bank of Dallas \\ Globalization and Monetary Policy Institute \\ Working Paper No. 5 \\ http://www.dallasfed.org/assets/documents/institute/wpapers/2007/0005.pdf
}

\title{
Production Sharing and Real Business Cycles in a Small Open Economy*
}

José Joaquín López

Federal Reserve Bank of Dallas

December 2007

\begin{abstract}
Production sharing and vertical specialization account for a significant share of trade between developed and developing countries. The Mexican maquiladora industry provides an ideal example of production sharing in a small open economy. The typical 'maquila' imports most of its inputs from and exports all its output to the United States. This article tries to determine to what extent production sharing, as in the Mexican maquiladora, can serve as a transmission mechanism of business cycles in small open economies. We utilize a simple two-sector small open economy model of real business cycles that incorporates production sharing in the traded sector. The transmission channel of business cycles is introduced in the model via demand shocks to the traded sector, originated in the United States' manufacturing sector. The model is successful in replicating real business cycles statistics for the maquiladora sector, as well as some of the characteristics of the non-traded sector.
\end{abstract}

JEL codes: E32, F14, F41

\footnotetext{
* José Joaquín López, Research Department, Federal Reserve Bank of Dallas, 2200 N. Pearl Street, Dallas, TX 75201. 915-521-5212. joaquin.lopez@dal.frb.org. I thank Charles Becker, Kim Ruhl, Stephanie Schmitt-Grohé, Martin Uribe, Mark Wynne and seminar participants at Duke University and the University of Texas at Austin for helpful comments and suggestions. All remaining errors are my sole responsibility. The views in this paper are those of the author and do not necessarily reflect the views of the Federal Reserve Bank of Dallas or the Federal Reserve System.
} 


\section{Introduction}

The importance of intra-industry trade and vertical specialization in trade growth has been well documented (Hummels, Ishii and Yi, 2001; Yi, 2003). On the other hand, the role played by production sharing between developed countries and their trading partners in the international transmission of business cycles has also motivated some of the recent literature on international real business cycles (Kose and Yi, 2001; Burstein, Kurz and Tesar, 2005).

This relationship between production sharing and business cycles seems to matter most in developing countries where intermediate goods are produced using imported inputs, and then shipped to another country for the final stage of production. In the case of Mexico, the maquiladora industry produces intermediate manufactures, importing most of its inputs from and exporting most of its output to the United States. This paper tries to determine the extent to which industries that are involved in production sharing, such as the Mexican maquiladora, have become a channel for the transmission of business cycles from the final-stage country (i.e., the U.S.) to the intermediate-stage country (i.e., Mexico). We utilize a simple two-sector model of real business cycles in a small open economy that incorporates production sharing in the traded sector. The transmission mechanism of the business cycle is introduced in the model via demand shocks to home's (Mexico) traded sector, originating in the manufacturing sector of the foreign country (the United States).

The rest of the paper is organized as follows. The second section presents some of the relevant facts about the maquiladora industry and its relation with U.S. manufacturing. The third section reviews some of the literature on international business 
cycles and small open economies and presents evidence on the correlation between Mexico and U.S. business cycles. The model is introduced in the fourth section. Results are presented in the fifth part of the paper. Finally, conclusions and recommendations for future research comprise the sixth section.

\section{Trade and the Mexican maquiladora}

The maquiladora program was established by the Mexican government in 1965 as a means to alleviate the negative effects caused by the conclusion of the U.S. bracero program in 1964. The bracero was a contract-based temporary labor program initiated in 1942 in a joint effort by the United States and Mexico that provided farm workers to the U.S. agriculture labor market. When many participants of the bracero program returned to Mexico after its conclusion, a significant portion of them found themselves out of work back home.

Under the maquila program, foreign companies are allowed to import inputs into Mexico duty-free, as long as the final output is exported. As the U.S. and Mexico became more integrated throughout the years, this industry has grown to the extent of producing more than half of Mexico's non-oil exports. Although it is not mandatory, these plants have tended to locate along the Mexican side of the U.S.-Mexico border, making that regional economy one of the most dynamic in Mexico.

The Mexican maquiladora is yet another example of production sharing, where the production process of a final good is divided into stages. In each stage, an intermediate good is produced and then shipped to another country for the next stage of production, until it reaches the country and stage where the final good is produced. 


\section{Aggregate fluctuations in small open economies}

Two decades ago, after Mexico’s accession to GATT, there was a popular saying among different observers of the Mexican economy: "When the U.S. sneezes, Mexico gets the flu." This colloquial observation of the international transmission of business cycles from the United States to Mexico seems to be supported by the data. Fluctuations in Mexico's GDP are highly correlated with fluctuations in U.S. GDP. During the period 1990-2005, the correlation between H-P-filtered quarterly GDP series for Mexico and the United States was 0.54 . Such correlation is even more noticeable in the NAFTA era (1994-2005), at 0.70 .

Within the basic framework for closed economies provided by Kydland and Prescott (1982), productivity disturbances (in a neoclassical growth model) motivate adjustment of savings and investment to smooth consumption, and a reallocation of time between labor and leisure. The closed-economy model has succeeded in replicating some stylized facts such as the pro-cyclicality of fluctuations in consumption, investment and employment, the variability of investment relative to output and consumption, and persistence in macro-aggregates.

International Real Business Cycles

Backus, Kehoe and Kydland (1992) studied international business cycles in a similar framework for large open economies and started an important discussion regarding counterfactual predictions of the workhorse model. In their theoretical economy, the cross-country correlation of consumption is higher than that of output, standing in sharp contrast with the empirical evidence. 
The main difference between the standard real business cycle model and the small open economy model is the structure of the financial markets. In the standard model, financial markets are complete, meaning that state-contingent claims can be traded, providing full insurance against the business cycle. In the small open economy model, even though financial markets are perfectly competitive, they are not complete, and the prevailing interest rate is exogenously determined (Mendoza, 1991). This implies that, while there is no room for arbitrage, claims contingent upon realizations of the state of the economy cannot be written. An extreme case of incomplete markets occurs under financial autarky.

Financial autarky in a given country can arise endogenously from the limited enforcement of international contracts (Heathcote and Perri, 2003). In that article, the authors compared the usual business cycle statistics, as well as cross-country correlations, with those generated by models in which economies trade a single, non-contingent bond, and those with complete markets. The authors conducted their analysis for a range of values for the elasticity of substitution between domestic and foreign goods (the Armington elasticity), and for a range of specifications for the productivity shocks that are the source of uncertainty in these models. The authors found that the financial autarky model always behaves differently than a model with complete markets, and that it is closest to the data along most dimensions.

Mendoza (1991a; 1991b) provided the basic framework for studying economic fluctuations in a small open economy. His model incorporated incomplete financial markets and terms of trade shocks into the workhorse model of real business cycles in closed economies previously developed by Kydland and Prescott (1982). In addition to 
the standard real business cycle statistics, the model presented by Mendoza analyzed a number of salient features of fluctuations in open economies, namely, the positive correlation of savings and investment, and the counter-cyclicality of the current account and the trade balance. The model is successful in replicating some of the empirical regularities of open economies, specifically, the positive correlation between savings and investment, and the tendency of trade balance and foreign assets to move against the business cycle. However, the model exaggerates the pro-cyclical correlation between consumption and output. The author suggests the addition of non-traded goods as an extension to the model that could help reduce the excessive consumption-output correlation.

Schmitt-Grohé and Uribe (2003) made a quantitative comparison of several modifications to the standard small open economy model. The first approach analyzed by the authors is a model with Uzawa-type preferences and capital adjustment costs. The second model includes a debt-elastic interest rate premium. The third variant is a model with convex portfolio adjustment costs. The fourth model features complete asset markets, while the fifth is the standard model without any stationarity-inducing features. The comparison is made via unconditional second moments and impulse response functions. Their main conclusion is that, regardless of different specifications, all models provide very similar dynamics at business-cycle frequencies.

\section{A two-sector small open economy model of real business cycles with production sharing}

This section introduces a two-sector small open economy model that incorporates non-traded goods and production sharing in the traded sector. The model is similar to that 
presented in Burstein, et al. (2006) in the way value added in the traded sector (maquiladora) is modeled, as well as in the origin of the foreign shocks. They introduce a multi-country international real business cycle model with production sharing, while the model presented here considers only the case of a small open economy.

While it borrows from previous theoretical developments, the model includes features that have not been used in conjunction in previous studies, namely, the presence of non-traded goods (as suggested by Mendoza, 1991) and financial autarky (as in Heathcote and Perri, 2003), combined with production sharing and foreign-demand shocks (as in Burstein, et al, 2006). Another important distinction is that this model does not include any capital adjustment costs or time to build restrictions as in Mendoza (1991) or Kydland and Prescott (1982). As we will see later, abstracting from investment frictions provides some insights on the modeling of aggregate fluctuations in emerging markets.

\section{Technology, financial and trade structure}

The economy produces two goods indexed as $\mathrm{N}$ and $\mathrm{T}$, so as to indicate nontraded and traded, respectively. The traded good is consumed, invested or exported, while the non-traded good is either consumed or invested. Technologies exhibit constant returns to scale in the Cobb-Douglas tradition.

$$
\begin{aligned}
& Y_{t}^{N}=A_{t} K_{t}^{N^{\alpha}} N_{t}^{N^{1-\alpha}} \\
& Y_{t}^{T}=A_{t}\left[K_{t}^{T^{\alpha}} N_{t}^{T^{(1-\alpha)}}\right]^{\omega} M_{t}^{1-\omega}
\end{aligned}
$$


Where $K$ is the service flow from the capital stock, and $N$ is labor. $M$ is an imported input and $\omega$ is the share of value added on the production of the traded good. $A_{t}$ is a productivity shock, common to both sectors, which is assumed to follow a process of the form:

$\ln A_{t+1}=\rho \ln A_{t}+\varepsilon_{t+1}$

Where $\varepsilon_{t}$ is an i.i.d. disturbance with zero mean and variance $\sigma_{\varepsilon}^{2}$

The laws of motion for capital in the non-traded and traded sectors are:

$I_{t}^{N}=K_{t+1}^{N}-(1-\delta) K_{t}^{N}$

$I_{t}^{T}=K_{t+1}^{T}-(1-\delta) K_{t}^{T}$

For simplicity, this economy is assumed to be under financial autarky. Therefore, this open economy is small in the sense that demand shocks affecting the traded sector are exogenously determined. Heathcote and Perri (2002) show that a two-country, twogood, international business cycle model with financial autarky can account for empirical regularities such as volatility in the terms of trade and cross-country consumption, output, investment and employment correlations.

Manufacturing firms in the foreign country solve the traditional profit maximization problem:

$\max _{\left\{X_{t}, F_{t}\right\}} P_{t}\left[\phi X_{t}^{1-\sigma}+(1-\phi) F_{t}^{1-\sigma}\right]^{\frac{1}{1-\sigma}}-P_{t}^{X} X_{t}-F_{t}$ 
Where $(1 / \sigma)$ is the elasticity of substitution between intermediate goods from the home country $\left(\mathrm{X}_{\mathrm{t}}\right)$ and intermediate goods from elsewhere $\left(\mathrm{F}_{t}\right.$, which is a numeraire). The resulting unit-demand for home's traded good is given by:

$X_{t}=\left[\phi+(1-\phi)^{\frac{1}{\sigma}}\left(\frac{P_{t}^{X}}{\phi}\right)^{\frac{1-\sigma}{\sigma}}\right]^{\frac{1}{\sigma-1}}$

Multiplying this unit-demand function by total manufacturing output in the foreign country $D_{t} Y_{t}^{U S}$, we obtain total demand for maquiladora-goods $\left(X_{t}^{T}=D_{t} Y_{t}^{U S} X_{t}\right)$. Foreign output is assumed to be affected by $D_{t}$, which is an exogenous shock common to all firms in the foreign country, such that:

$\ln D_{t+1}=\psi \ln D_{t}+u_{t+1}$

where $u_{t}$ is an i.i.d. disturbance with zero mean and variance $\sigma_{u}^{2}$

Under financial autarky, trade must be quid pro quo, that is, the value of the exported goods should equal the value of the imported inputs at any given time:

$P_{t}^{X} X_{t}^{T}-P_{t}^{M} M_{t}=0$

Rearranging the previous equation yields an expression for the economy's terms of trade:

$\frac{P_{t}^{X}}{P_{t}^{M}}=\frac{M_{t}}{X_{t}^{T}}$

Market clearing in both sectors implies:

$C_{t}^{N}+I_{t}^{N}+=Y_{t}^{N}$

$C_{t}^{T}+I_{t}^{T}+X_{t}^{T}-M_{t}=Y_{t}^{T}$ 


\section{Preferences}

Households in this economy are infinitely-lived and allocate consumption and labor intertemporally so as to maximize:

$$
U\left(C_{t}, 1-N_{t}^{N}-N_{t}^{T}\right)=E_{0} \sum_{t=0}^{\infty} \beta^{t}\left[\ln \left(C_{t}\right)+\theta\left(1-N_{t}^{N}-N_{t}^{T}\right)\right]
$$

where non-traded and traded goods are consumed according to $C_{t}=C_{t}^{N^{\mu}} C_{t}^{T^{1-\mu}}$,

and $N_{t}^{N}+N_{t}^{T}+L_{t}=1$, where $L_{t}$ represents leisure.

Given preferences, technology, prices and market clearing conditions, the social planner chooses sequences $\left\{K_{t+1}^{N}, K_{t+1}^{T}, C_{t}, N_{t}^{N}, N_{t}^{T}\right\}_{t=1}^{\infty}$ to solve the following problem:

$\max E_{0} \sum_{t=0}^{\infty} \beta^{t}\left[\ln C_{t}+\theta\left(1-N_{t}^{N}-N_{t}^{T}\right)\right]$

s.t.

$K_{t+1}^{N}-(1-\delta) K_{t}^{N}+C_{t}^{N}=A_{t} K_{t}^{N^{\alpha}} N_{t}^{N^{1-\alpha}}$

$K_{t+1}^{T}-(1-\delta) K_{t}^{T}+X_{t}^{T}-\left(\frac{P_{t}^{M}}{P_{t}^{X}}\right) M_{t}+C_{t}^{T}=A_{t} K_{t}^{T^{\alpha \omega}} N_{t}^{T^{(1-\alpha) \omega}} M_{t}^{1-\omega}$

$X_{t}^{T}=\left(\frac{P_{t}^{M}}{P_{t}^{X}}\right) M_{t}$

$\ln A_{t+1}=\rho \ln A_{t}+\varepsilon_{t+1}$

$\ln D_{t+1}=\psi \ln D_{t}+u_{t+1}$ 
The first order conditions imply:

$$
\begin{aligned}
& 1=\beta E\left[\left(\frac{C_{t+1}^{N}}{C_{t}^{N}}\right)^{-1} R_{t+1}^{N}\right] \\
& 1=\beta E\left[\left(\frac{C_{t+1}^{T}}{C_{t}^{T}}\right)^{-1} R_{t+1}^{T}\right]
\end{aligned}
$$

$R_{t+1}^{N}=\alpha A_{t+1}\left(\frac{N_{t+1}^{N}}{K_{t+1}^{N}}\right)^{1-\alpha}+(1-\delta)$

$R_{t+1}^{T}=\alpha \omega A_{t+1}\left(\frac{K_{t+1}^{T}}{N_{t+1}^{T}}\right)^{\alpha \omega}\left(\frac{N_{t+1}^{T}}{M_{t+1}}\right)^{\omega} M_{t+1}+(1-\delta)$

$K_{t+1}^{N}=A_{t} K_{t}^{N^{\alpha}} N_{t}^{N^{1-\alpha}}+(1-\delta) K_{t}^{N}-C_{t}^{N}$

$K_{t+1}^{T}=A_{t} K_{t}^{T^{\alpha \omega}} N_{t}^{T^{(1-\alpha) \omega}} M_{t}^{1-\omega}+(1-\delta) K_{t}^{T}-X_{t}^{T}+\left(\frac{P_{t}^{M}}{P_{t}^{X}}\right) M_{t}-C_{t}^{T}$

$X_{t}^{T}-\left(\frac{P_{t}^{M}}{P_{t}^{X}}\right) M_{t}=0$

$\ln A_{t+1}-\rho \ln A_{t}=0$

$\ln D_{t+1}-\psi \ln D_{t}=0$

And the intra-temporal choices regarding the imported input and labor:

$$
\begin{aligned}
& \frac{(1-\omega) A_{t} K_{t}^{T^{\omega \alpha}} N_{t}^{T^{\omega(1-\alpha)}} M_{t}^{-\omega}}{C_{t}^{T}-1}=\frac{P_{t}^{M}}{P_{t}^{X}} \\
& \theta=(1-\alpha) \frac{A_{t}}{C_{t}}\left(\frac{K_{t}^{N}}{N_{t}^{N}}\right)^{\alpha}=(1-\alpha) \omega \frac{A_{t}}{C_{t}}\left(\frac{K_{t}^{T}}{N_{t}^{T}}\right)^{\alpha \omega}\left(\frac{M_{t}}{N_{t}^{T}}\right)^{1-\omega}
\end{aligned}
$$




\section{Parameterization and calibration}

According to Burstein, et al (2005), the maquiladora industry exports one-dollar worth of output per every 75 cents it imports. Following their calculation, we set the value added share $\omega=0.25$. Shares for capital in the production function can be obtained from available data (Instituto Nacional de Estadística, Geografía e Informática, INEGI). We set $\alpha=0.20$ for the non-traded sector and $\alpha=0.32$ for the traded sector. The share of Mexican goods in U.S. manufacturing intermediate imports $(\varphi=0.115)$ is also obtained from the data (Trade Statistics, U.S. Census Bureau). The depreciation rate and the preference parameters are calibrated within the tradition in the real business cycle literature $(\delta=0.03, \beta=0.98, \theta=2)$. The elasticity of substitution between Mexican maquiladora inputs and inputs from elsewhere in U.S. manufacturing used to obtain these results $(0.13)$ is within the range of estimates from 163 U.S. manufacturing sub-sectors calculated by Reinert and Roland-Holst (1992). Productivity and foreign demand shocks are build to match the persistence and volatility of the H-P-filtered natural logarithms of Mexican GDP and U.S. Industrial Production, respectively.

\section{The solution method}

The model is solved using a first order, logarithmic, approximation around the non-stochastic steady state, as suggested by Schmitt-Grohe and Uribe (2003). The optimality conditions represent a system of nonlinear stochastic first-order difference equations that can be expressed as the following vector:

$$
E_{t} f\left(x_{t+1}, x_{t}, y_{t+1}, y_{t}\right)=0
$$


Where $E_{t}$ denotes the mathematical expectation operator at time $t$. The vector $x_{t}$ denotes the vector of state variables and $y_{t}$ represents the vector of control variables. We can distinguish between those elements of $x_{t}$ that are endogenous (capital), from those that are exogenous (productivity and foreign demand). Specifically, let $K_{t}=\left[K_{t}^{N} ; K_{t}^{T}\right]$ and $Z_{t}=\left[A_{t} ; D_{t} ; X_{t}\right]$, then $x_{t}=\left[K_{t} ; Z_{t}\right]^{\prime}$. The vector of control variables, $y_{t}$ includes consumption, labor and the imported input.

The objective is to find policy functions $y_{t}=g\left(x_{t}\right)$ and $x_{t+1}=h\left(x_{t}\right)+\eta \varepsilon_{t+1}$ such that (25) is satisfied. This is accomplished by computing the non-stochastic steady state of the system, and then taking a log-linear approximation around that point ${ }^{1}$. Results from the procedure are discussed in the following section.

\section{Results}

Simulated second moments and their data counterparts are reported in Table 1. The model successfully mimics some of the business cycle characteristics of the Mexican economy. In particular, simulated estimates for the volatility of maquiladora output and employment are within a $10 \%$ range from their data equivalents. The model fails to replicate the volatility of the non-traded aggregates, but successfully reproduces the correlation between non-maquila output and non-maquila investment. Also, in most cases, the model provides persistence (autocorrelation) coefficients that are within a two standard error threshold from their econometrically estimated counterparts.

The absence of capital adjustment costs or time to build causes the model to exaggerate the volatility of investment in the traded sector. This result is in line with a

\footnotetext{
${ }^{1}$ MATLAB $^{\odot}$ codes for the solution method are provided by Schmitt-Grohé and Uribe and can be found at http://www.econ.duke.edu/\%7Euribe/closing.htm
} 
vast literature on real business cycles in industrialized countries. This implies that the modeling of business-cycle capital dynamics in emerging economies, at least in the case of Mexico, is not very different from that of a developed country.

The model is very sensitive to changes in some of the parameters. In particular, small variations in the discount factor and in the elasticity of substitution between intermediate goods in the U.S. cause large variations in the simulated second moments. The calibrated value for the Armington elasticity (0.13) is consistent with time-series and real business cycles estimates (Ruhl, 2005).

\section{Conclusion}

The high correlation of U.S. and Mexico de-trended output in the NAFTA era, and the increasing importance of the maquiladora industry in Mexico's exports suggest that this industry acts like a mechanism for the transmission of business cycles from the U.S. to Mexico. This paper presents a two-sector model of real business cycles in a small open economy that incorporates production sharing in the traded sector. The model is parameterized to match the structure of the observed structural parameters in the Mexican economy and the volatility of U.S. industrial production.

The model is successful in replicating maquiladora (traded) sector business-cycle dynamics as well as some of the characteristics of the non-traded sector. The present model can be extended to incorporate incomplete markets, which allows current account dynamics not present in this model that can account for the non-captured behavior of some aggregates. Standard modifications such as those presented in Schmitt-Grohe and Uribe (2003) are also feasible and may provide a better representation of the U.S.-Mexico business cycle synchronization. 


\section{Table 1. Simulated and Actual Second Moments}

$\begin{array}{lcc} & \text { Model } & \text { Data } \\ & \text { Std Deviation } & \text { Std Deviation } \\ \text { Output (N) } & 0.00 & 2.2 \\ \text { Output (T) } & 4.02 & 4.27 \\ \text { Consumption (N) } & 0.00 & 4.09 \\ \text { Investment (N) } & 0.00 & 9.20 \\ \text { Investment (T) } & 10.96 & 6.00 \\ \text { Employment (N) } & 0.00 & 1.97 \\ \text { Employment (T) } & 5.75 & 5.24 \\ & & \\ \text { Output (N) } & \text { Autocorrelation } & \text { Autocorrelation* } \\ \text { Output (T) } & 0.97 & 0.83(.068) \\ \text { Consumption (N) } & 0.88 & 0.76(.07) \\ \text { Investment (N) } & 0.99 & 0.80(.07) \\ \text { Investment (T) } & 0.86 & 0.74(.08) \\ \text { Employment (N) } & 0.88 & 0.77(.07) \\ \text { Employment (T) } & 0.90 & 0.85(.05) \\ & 0.88 & 0.93(.04)\end{array}$

Corr. W/Output (N) Corr. W/Output (N)

$\begin{array}{lll}\text { Output (N) } & 1.00 & 1.00 \\ \text { Output (T) } & 0.15 & 0.42 \\ \text { Consumption (N) } & 0.85 & 0.91 \\ \text { Investment (N) } & 0.90 & 0.92 \\ \text { Investment (T) } & 0.10 & -0.49 \\ \text { Employment (N) } & 0.95 & 0.79 \\ \text { Employment (T) } & 0.09 & 0.53\end{array}$

*Standard errors in parentheses. 


\section{References}

Backus, David K., Patrick J. Kehoe and Finn E. Kydland (1992). “International Real Business Cycles," Journal of Political Economy, Vol. 100, No. 4, August, 745-775.

Burstein, Ariel, Christopher J. Kurz and Linda Tesar (2005). "Trade, Production Sharing and the International Transmission of Business Cycles," mimeo, University of California, Los Angeles and University of Michigan.

Heathcote, Jonathan and Fabrizio Perri (2002). "Financial Autarky and International Business Cycles," Journal of Monetary Economics, 49, pp 601-627.

Hummels, David, Jun Ishii and Kei-Mu Yi (2001). "The nature and growth of vertical specialization in world trade," Journal of International Economics, vol. 54, No. 1, June, pp 75-96.

Kose, M. Ayhan and Kei-Mu Yi (2006). "Can the standard international business cycle model explain the relation between trade and comovement?," Journal of International Economics, Vol. 68, No. 2, March, pp 267-295.

Kydland, Finn and Edward C. Prescott (1982). "Time to Build and Aggregate Fluctuations," Econometrica, Vol. 50, No. 6, November, pp 1345-1370. Mendoza, Enrique G. (1991a). "Real Business Cycles in a Small Open Economy," American Economic Review, Vol. 81, No. 4, September, pp 797-818.

Mendoza, Enrique G. (1991b). "Capital Controls and the Gains from Trade in a Business Cycle Model of a Small Open Economy," IMF Staff Papers. 
Reinert, Kenneth A. and David W. Roland-Holst (1992). “Armington Elasticities for United States Manufacturing Sectors," Journal of Policy Modeling, Vol. 14, No. 5, pp. 631-639.

Ruhl, Kim J. (2005). “The Elasticity Puzzle in International Economics,” mimeo, University of Texas at Austin.

Schmitt-Grohé, Stephanie and Martín Uribe (2003). “Closing Small Open Economy Models," Journal of International Economics, Vol. 61, No. 1, pp 163-185.

Yi, Kei-Mu (2003). “Can Vertical Specialization Explain the Growth of World Trade?” Journal of Political Economy, Vol. 111, No.1, pp 52-102. 